\title{
Congenital anomaly of pancreas divisum as cause of obstructive pain and pancreatitis
}

\author{
P B COTTON
}

\author{
From the Gastrointestinal Unit, The Middlesex Hospital, London
}

SUMmaRY Pancreas divisum occurs when the embryological ventral and dorsal parts of the pancreas fail to fuse, so that pancreatic drainage is mainly through the accessory papilla. In 169 patients with primary biliary tract disease who underwent pancreatography incidental to endoscopic cholangiography, the incidence of pancreas divisum was 3.6\%. Among 78 patients with unexplained recurrent pancreatitis, the incidence was $25.6 \%$. The hypothesis that the duct anomaly can cause obstructive pain and pancreatitis is presented, and supported by a detailed analysis of 47 patients with the condition.

Congenital anomalies of the pancreatic duct system are recognised by anatomists ${ }^{1}$ and by a few surgeons interested in operative or necropsy pancreatography ${ }^{2}$; but the increasing use of endoscopic pancreatography $^{3}$ has demonstrated the existence of duct anomalies to a much wider audience. Clinicians may occasionally see a patient with an annular pancreas, but the 'pancreas divisum' is far more common. This anomaly occurs when the ventral and dorsal pancreatic elements fail to fuse in utero; as a result, the bulk of the pancreas drains through the accessory papilla. We have previously suggested that drainage may therefore be inadequate, and give rise to obstructive pancreatic pain and pancreatitis. ${ }^{4}$ This paper presents a detailed analysis of 47 patients with pancreas divisum, and discusses its clinical relevance.

\section{Anatomy}

The adult human pancreas is formed from dorsal and ventral elements which normally fuse in the second month of intrauterine life (Fig. 1). The ventral bud arises with the biliary system and eventually forms the inferior and posterior part of the pancreatic head; the dorsal part provides the remainder of the head, and the whole of the body and tail of the gland. Normally the duct systems fuse, so that the gland drains almost entirely through Wirsung's duct into the major papilla of Vater, in close association with the bile duct (Fig. 1C). The duct connecting the accessory papilla and the main duct usually remains, as Santorini's duct (Fig. 2). When embryo-

Received for publication 20 August 1979 logical development is halted at the middle stage (Fig. 1B), the ventral part remains separate as an 'isolated ventral pancreas', and the condition is called 'pancreas divisum'. Santorini's duct and the accessory papilla then form the only excretory pathway for the bulk of the gland. In this situation, endoscopic cannulation of the main papilla of Vater outlines the bile duct, and the small ventral pancreas (Figs. 3 and 4). Opacification of the bulk of the pancreas (dorsal part) requires cannulation of the accessory papilla and Santorini's duct (Figs 5, 6). Occasionally, the ventral duct system is rudimentary or absent (Fig. 1D); no pancreatogram can be obtained via the major papilla, and the anomaly will only be detected if accessory cannulation is attempted and succeeds.

\section{Methods}

\section{PATIENTS}

Between January 1974 and July 1978, 1215 patients underwent endoscopic retrograde cholangiopancreatography (ERCP) in this unit. In many patients only cholangiography was required, and pancreatography was not attempted. Pancreatography was indicated clinically in 877 patients, and was achieved in 810. Pancreas divisum was diagnosed in 47 patients, an overall incidence of $5.8 \%$ of total pancreatograms (Table 1). Among patients with primary biliary tract disease (all those with gallstones, strictures, and tumours, but excluding unexplained post-cholecystectomy pain), the incidence was $3.6 \%$. This was considerably less than the incidence $(16.4 \%)$ in 188 patients with recurrent pancreatitis (both chronic and relapsing acute). 


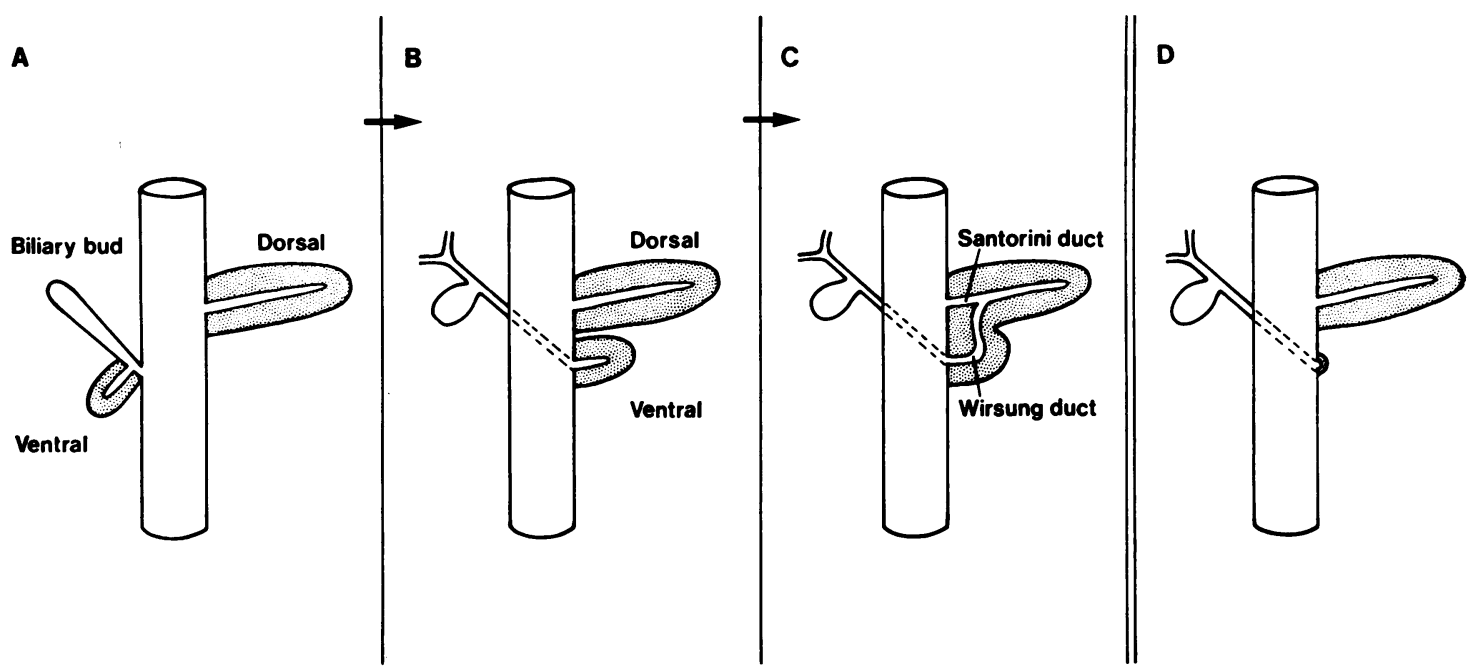

Fig. 1 Embryological development of the pancreas. Stage $C$ indicates the normal adult arrangement. Stages $B$ and $D$ are examples of pancreas divisum.

There were 83 patients whose pancreatitis was not obviously associated with alcohol abuse, gallstones, or trauma. The incidence of pancreas divisum among this group of patients with 'idiopathic recurrent pancreatitis' was no less than $25.6 \%$ (Table 1).

The 47 patients diagnosed at ERCP as having pancreas divisum were divided into four clinical groups (Table 2). There were nine patients (group A) in whom the anomaly did not appear to be clinically relevant; the symptoms leading to ERCP were adequately explained on a non-pancreatic basis (Table 3), and follow-up (at one to four years) revealed no pancreatic symptoms. Tables 4,5 , and 6 give details of the patients in whom the anomaly may be of clinical significance. Twenty-nine of the 47 patients had pancreatitis. In 19 (group B, Table 4) no cause was evident. In the other 10 patients (group $\mathrm{C}$, Table 5) pancreatitis was associated with significant alcohol abuse. The final nine patients (group D, Table 6) had recurrent attacks of severe and typical pancreatic type pain; they differed from those in group B only in so far as specific pancreatic investigations showed no evidence of pancreatic damage (Table 6). None of these nine patients was a heavy drinker; but, in some, attacks could be precipitated

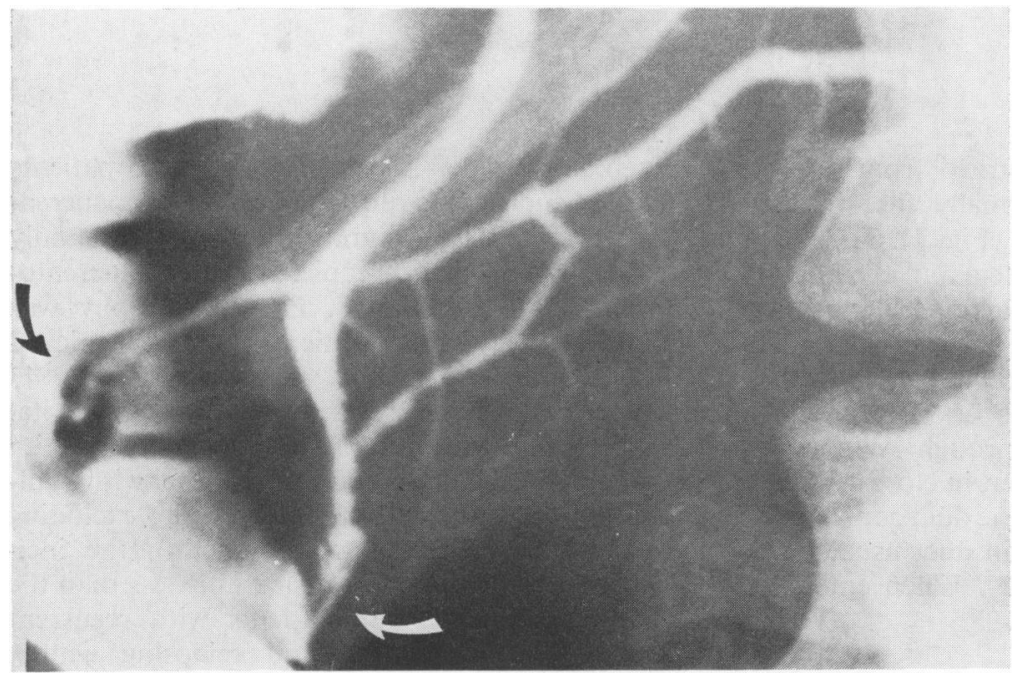

Fig. 2 Normal duct arrangements. The main papilla (white arrow) has been cannulated, outlining Wirsung's duct and the bile duct. Contrast has flowed back down Santorini's duct to the accessory papilla (black arrow). 
Table 1 Incidence of pancreas divisum at ERCP

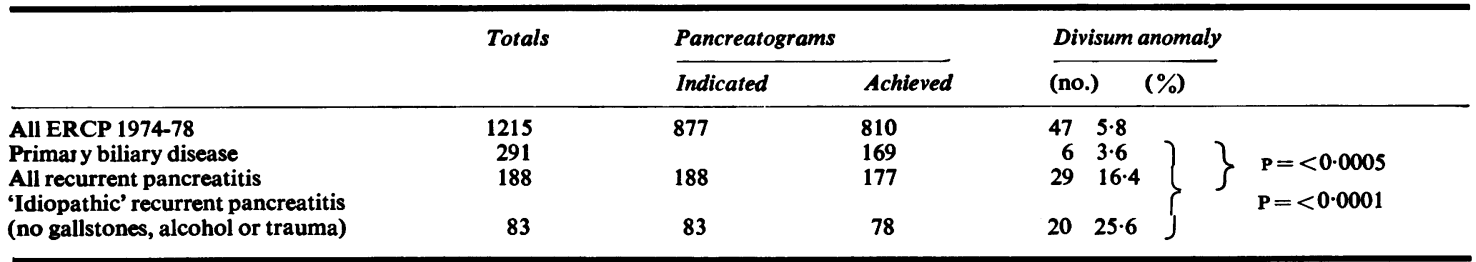

by a rich meal or a single alcoholic drink.

Previous management of all the 28 patients with previously unexplained recurrent pancreatitis and pancreatic type pain (groups B and D) had proved difficult. Typically they had had repeated admissions to hospital and numerous negative investigations, over periods of up to 30 years. Exploratory laparotomy had been performed on 16 patients, of whom 12 had surgical procedures which proved unhelpful; eight had lost normal gallbladders, two had had vagotomies, and two had had surgical sphincteroplasties at the major papilla.

\section{PANCREATOGRA PHY}

Overall results of pancreatography are shown in Tables 4, 5, and 6, and examples in Figs. 3-9. A ventral pancreatic system was identified in 39 patients, and was radiologically normal in all except one, a heavy drinker (Table 5 , no. 34). The possible significance of pancreas divisum was not appreciated early in the series. Thus cannulation of the accessory papilla was not always attempted (and was not necessary in patients with biliary problems). However, accessory papilla cannulation did succeed and produced a dorsal pancreatogram

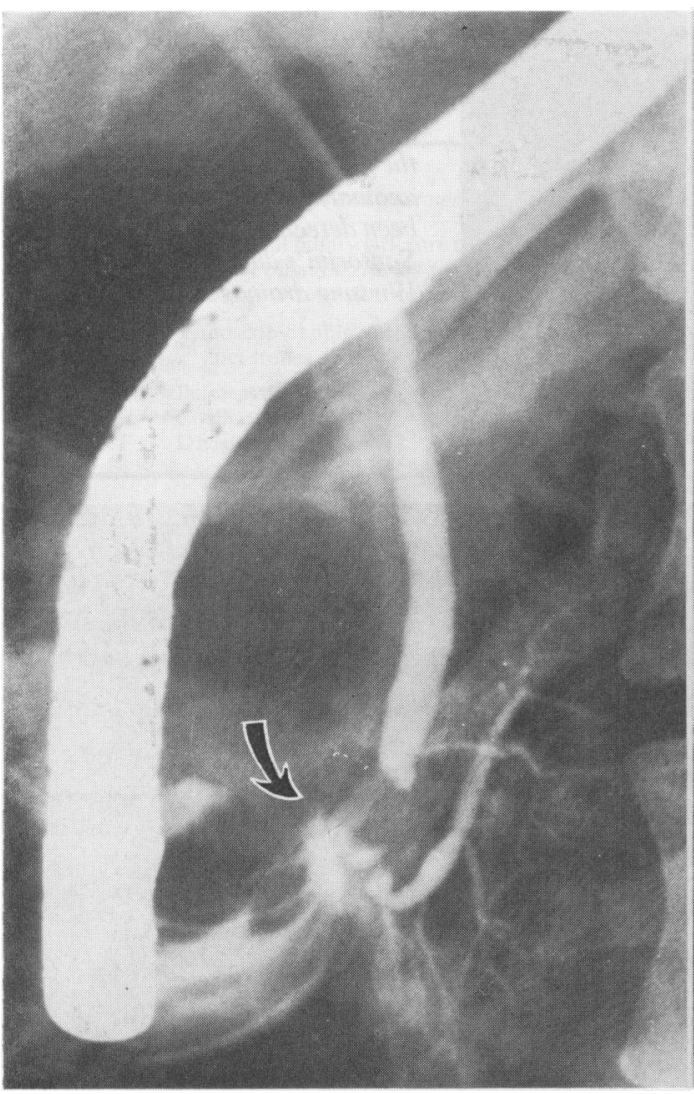

Fig. 3 Cannulation of the main papilla (arrow) has outlined the bile duct and a ventral pancreas.

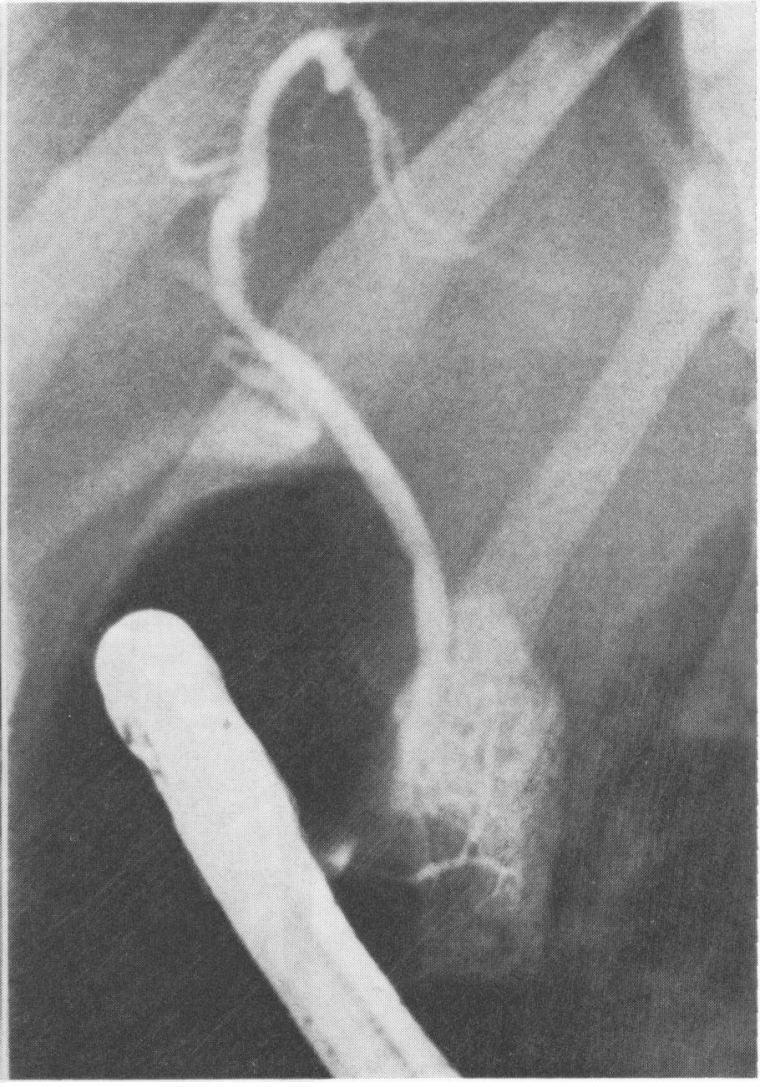

Fig. 4 As Fig. 3, except that more contrast has been injected to outline the extent of the parenchyma of the ventral pancreas. 
in 10 out of 27 attempts in patients with a ventral pancreas (Table 7, examples Figs. 5-9). Later still we realised that complete failure of pancreatography via the main papilla could result from pancreas divisum with a vestigial ventral element (Fig. 1D), and that accessory cannulation should always be attempted when standard pancreatography fails. In these circumstances accessory cannulation succeeded in eight patients (Table 7) (example Fig. 9). The failure rate cannot be stated, as the existence of this type of pancreas divisum can be identified only when dorsal pancreatography succeeds.

Dorsal pancreatograms were obtained in 17 of the 29 patients with pancreatitis (groups B and C).
Table 2 Clinical grouping of 47 patients with pancreas divisum

\begin{tabular}{lcll}
\hline Group & Total & Clinical status & $\begin{array}{l}\text { Anomaly } \\
\text { relevance }\end{array}$ \\
\hline A & 9 & $\begin{array}{l}\text { Definite non-pancreatic cause for } \\
\text { pain }\end{array}$ & Nil \\
B & 19 & $\begin{array}{l}\text { Idiopathic recurrent pancreatitis } \\
\text { Alcohol-associated pancreatitis } \\
\text { Cancreatic-type pain without } \\
\text { definite evidence of pancreatitis }\end{array}$ & $\begin{array}{l}\text { Probable } \\
\text { Possible } \\
\text { Probable }\end{array}$ \\
\hline
\end{tabular}

Four of the dorsal pancreatograms were achieved at the time of surgery. Fifteen of the dorsal pancreatograms were radiologically abnormal; in eight

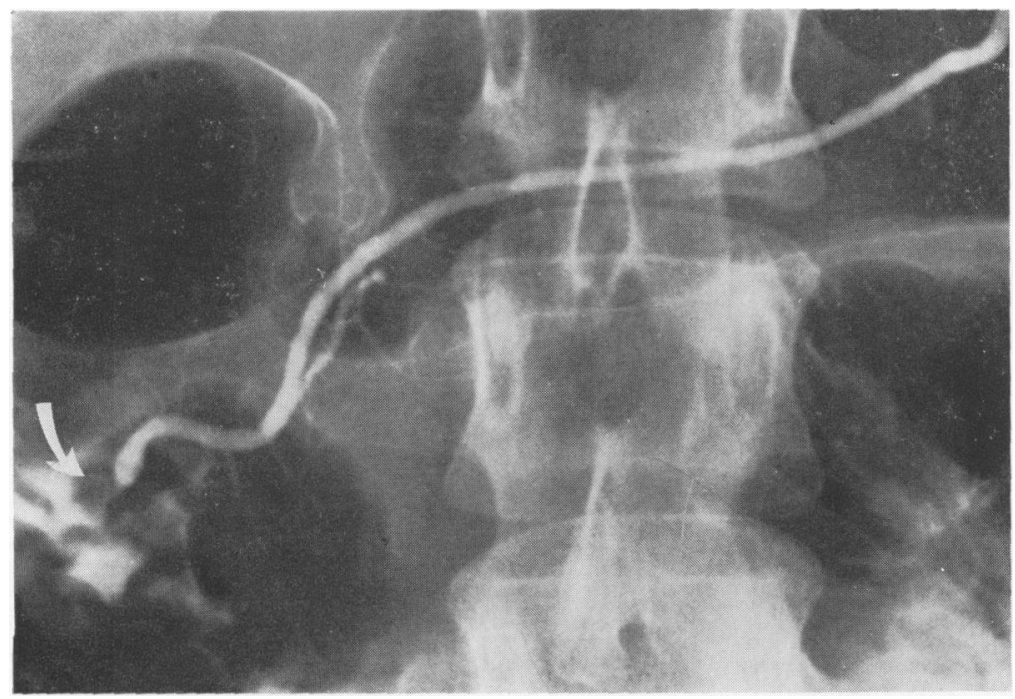

Fig. 5 Non-dilated dorsal duct system after cannulation of the accessory papilla (arrowed). There is pathological delay in contrast emptying after removal of the catheter. If this radiograph had been obtained at surgery by injection of the duct in the tail of the gland, the existence of an anomaly would probably not have been detected; in this case Santorini's duct resembles normal Wirsung drainage.

Fig. 6 Normal ventral and dorsal duct systems outlined by cannulating both papillae separately (arrows).

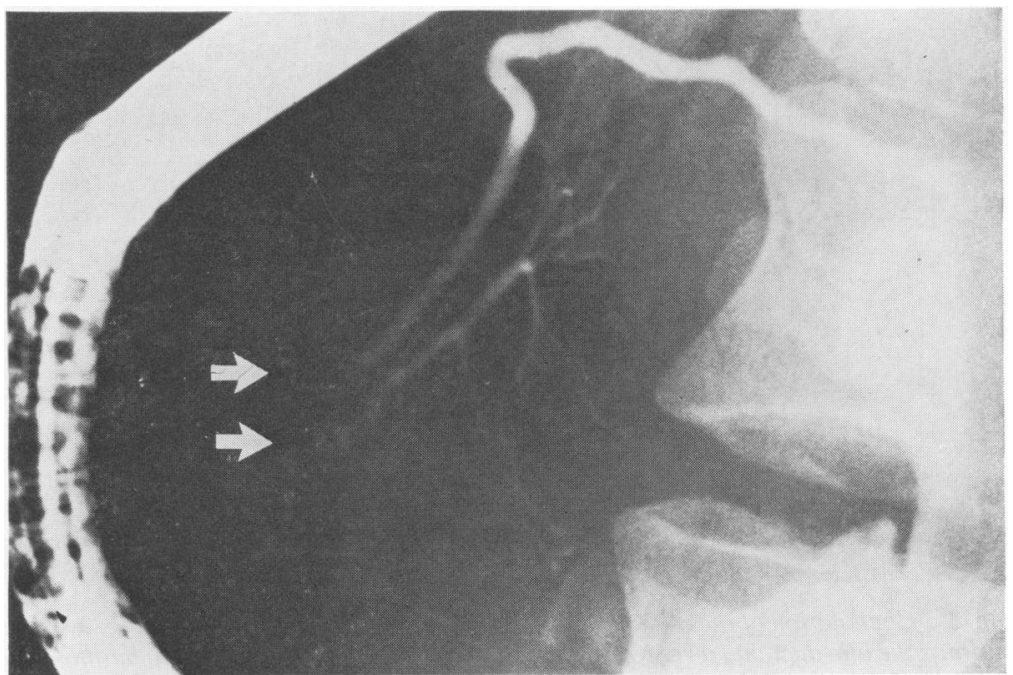


Table 3 Group $A$ patients with alternative diagnosis and no pancreatic pain.

\begin{tabular}{|c|c|c|c|}
\hline Patient & $\begin{array}{l}\text { Age/sex } \\
(y r)\end{array}$ & Other diagnosis and treatment & $\begin{array}{l}\text { Follow-up } \\
(y r)\end{array}$ \\
\hline $\begin{array}{l}1 \\
2 \\
3 \\
4 \\
5 \\
6 \\
7 \\
7 \\
8 \\
9\end{array}$ & 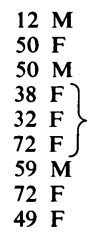 & $\begin{array}{l}\text { Congenital biliary stricture repaired } \\
\text { Primary biliary cirrhosis } \\
\text { Cholecystectomy for stones } \\
\text { Endoscopic sphincterotomy for bile } \\
\text { duct stones } \\
\text { Painless diabetes } \\
\text { Coeliac disease } \\
\text { Division of adhesions }\end{array}$ & $\begin{array}{l}4 \\
\text { Died } \\
3 \\
2 \\
1 \\
1 \\
2 \\
1 \\
2\end{array}$ \\
\hline
\end{tabular}

cases abnormal dorsal radiographs could be contrasted with normal ventral ducts (Tables 4 and 5, examples Figs 7 and 8 ).

By definition, all five dorsal pancreatograms obtained in group D patients were normal (Table 6).

\section{CLINICAL PROGRESS}

Patients have been followed up for periods of one to five years. By definition, all nine patients in group A have so far done well, after appropriate management of their non-pancreatic cause for symptoms. The nine patients in group $\mathrm{D}$ have continued to suffer episodes of pancreatic type pain, often sufficiently severe to require strong analgesia or hospital admission. Most would have warranted diagnostic laparotomy in earlier days, and two patients have subsequently been subjected to laparotomy (with negative results) to make certain that no other disease was present; none has yet undergone specific surgical procedures on the pancreas.

The 10 patients with alcohol associated pancreatitis (group C) have all predictably fared badly. Most have continued to drink and four have under-

Table 4 Clinical details of patients in group B (recurrent pancreatitis unassociated with alcohol abuse)

\begin{tabular}{|c|c|c|c|c|c|c|c|c|c|}
\hline \multirow[b]{2}{*}{ Patient } & \multirow[b]{2}{*}{$\begin{array}{l}\text { Age/sex } \\
(y r)\end{array}$} & \multirow[b]{2}{*}{$\begin{array}{l}\text { Years } \\
\text { pain }\end{array}$} & \multicolumn{4}{|c|}{ Evidence for pancreatitis } & \multicolumn{2}{|c|}{ Pancreatogram } & \multirow[b]{2}{*}{$\begin{array}{l}\text { Subsequent } \\
\text { surgery }\end{array}$} \\
\hline & & & Surgery & $\begin{array}{l}\text { Raised } \\
\text { amylases }\end{array}$ & $\begin{array}{l}\text { Abnormal } \\
P F T\end{array}$ & $\begin{array}{l}\text { Abnormal } \\
\text { scans }\end{array}$ & Ventral & Dorsal & \\
\hline 10 & $62 \mathrm{~F}$ & 20 & + & & + & & $\mathbf{N}$ & Abn & + \\
\hline 11 & $68 \mathrm{~F}$ & 5 & + & & & & $\mathbf{N}$ & & \\
\hline 12 & $72 \mathrm{~F}$ & 2 & & + & + & $\mathrm{US} / \mathrm{CT}$ & $\mathbf{N}$ & & \\
\hline 13 & $22 \mathrm{M}$ & 5 & & & Equiv & $\mathrm{CT}$ & $\mathbf{N}$ & & \\
\hline 15 & $50 \mathrm{M}$ & 3 & + & + & & & $\mathbf{N}$ & & \\
\hline 16 & $68 M$ & 10 & & & + & & $\mathbf{N}$ & & \\
\hline 17 & $34 \mathrm{M}$ & 1 & + & $\div$ & & $\mathrm{US} / \mathrm{CT}$ & $\mathbf{N}$ & Abn & + \\
\hline 18 & $56 \mathrm{~F}$ & 30 & + & + & Equiv & US/CT & $\mathbf{N}$ & Abn (op) & + \\
\hline 19 & $57 \mathrm{~F}$ & 5 & + & + & + & US & $\mathbf{N}$ & $\mathrm{N}$ & + \\
\hline 20 & $50 \mathrm{~F}$ & 1 & & & + & & $\mathbf{N}$ & & \\
\hline 21 & $62 \mathrm{~F}$ & 1 & & + & & & $\mathbf{N}$ & Abn & \\
\hline 22 & $43 \mathrm{M}$ & 3 & + & + & + & US & $\mathbf{N}$ & Abn (op) & + \\
\hline 23 & $47 \mathrm{M}$ & 3 & + & + & $\mathbf{N}$ & & & Abn & \\
\hline 25 & $40 \mathrm{~F}$ & 5 & + & + & Equiv & US & $\mathbf{N}$ & Abn (op) & + \\
\hline 26 & $43 \mathrm{M}$ & 4 & + & + & & & $\mathbf{N}$ & Equiv & \\
\hline 27 & $69 \mathrm{~F}$ & 2 & & & & & & Abn & \\
\hline 28 & $26 \mathrm{M}$ & 6 & + & + & & US & & Abn & + \\
\hline
\end{tabular}

PFT: pancreatic function test, usually secretin/pancreozymin study.

Equiv: equivocal. US : ultrasonography. CT: computerised axial tomography. N: normal. Abn: abnormal. Op: operative pancreatogram.

Table 5 Group C patients with alcohol associated pancreatitis

\begin{tabular}{|c|c|c|c|c|c|c|c|c|c|c|}
\hline \multirow[b]{2}{*}{ Patient } & \multirow[b]{2}{*}{$\begin{array}{l}\text { Age/sex } \\
(y r)\end{array}$} & \multirow[b]{2}{*}{$\begin{array}{l}\text { Years } \\
\text { pain }\end{array}$} & \multicolumn{5}{|c|}{ Evidence for pancreatitis } & \multicolumn{2}{|c|}{ Pancreatogram } & \multirow[b]{2}{*}{$\begin{array}{l}\text { Subsequent } \\
\text { surgery }\end{array}$} \\
\hline & & & Surgery & $\begin{array}{l}\text { Raised } \\
\text { amylases }\end{array}$ & $\begin{array}{l}\text { Abnormal } \\
\text { PFT }\end{array}$ & $\begin{array}{l}\text { Abnormal } \\
\text { scans }\end{array}$ & Calc & Ventral & Dorsal & \\
\hline .29 & $65 \mathrm{M}$ & 30 & & & & US & & $\mathbf{N}$ & & \\
\hline 30 & $35 \mathrm{~F}$ & 2 & & + & & US & & $\mathbf{N}$ & & \\
\hline 31 & $35 \mathrm{~F}$ & 5 & & + & + & & + & $\mathbf{N}$ & & \\
\hline 32 & $50 \mathrm{~F}$ & 10 & + & + & & US & + & & Abn & \\
\hline 34 & $33 \mathrm{M}$ & 4 & + & & & & + & Abn & Abn (op) & \\
\hline 35 & $51 \mathrm{~F}$ & 10 & + & & & US & & & Abn & + \\
\hline 36 & $43 \mathrm{M}$ & 8 & $\div$ & + & & US & & $\mathbf{N}$ & Abn & + \\
\hline 37 & $68 \mathrm{~F}$ & 1 & & & & US & + & $\mathbf{N}$ & & + \\
\hline 38 & $50 \mathrm{~F}$ & 5 & & + & & US & & $\mathbf{N}$ & & + \\
\hline
\end{tabular}

Abbreviations as for Table 4. In addition, calc: calcification of the pancreas on plain radiology. 
Table 6 Group D patients with pancreatic type pain, but no definite evidence of pancreatitis on investigation

\begin{tabular}{|c|c|c|c|c|c|c|c|}
\hline \multirow[t]{2}{*}{ Patient } & \multirow{2}{*}{$\begin{array}{l}\text { Age/sex } \\
(y r)\end{array}$} & \multirow{2}{*}{$\begin{array}{l}\text { Years } \\
\text { pain }\end{array}$} & \multirow{2}{*}{$\begin{array}{l}\text { Pancreas at } \\
\text { operation }\end{array}$} & \multirow[t]{2}{*}{$P F T$} & \multirow[t]{2}{*}{$U S$} & \multicolumn{2}{|c|}{ Pancreatogram } \\
\hline & & & & & & Ventral & Dorsal \\
\hline 39 & $24 \mathrm{M}$ & 5 & & $\mathbf{N}$ & $\mathbf{N}$ & $\mathbf{N}$ & \\
\hline 40 & $46 \mathrm{~F}$ & 2 & $\mathbf{N}$ & Equiv & $\mathbf{N}$ & & $\mathbf{N}$ \\
\hline 41 & $35 \mathrm{~F}$ & 12 & & $\mathbf{N}$ & $\mathbf{N}$ & $\mathbf{N}$ & $\mathbf{N}$ \\
\hline 42 & $45 \mathrm{~F}$ & 8 & & & $\mathbf{N}$ & $\mathbf{N}$ & $\mathbf{N}$ \\
\hline 43 & $20 \mathrm{M}$ & 5 & & $\mathbf{N}$ & $\mathbf{N}$ & $\mathbf{N}$ & \\
\hline 44 & $38 \mathrm{~F}$ & 8 & $\mathbf{N}$ & & & $\mathbf{N}$ & \\
\hline 45 & $38 \mathrm{~F}$ & 1 & $\mathbf{N}$ & & Equiv & $\mathbf{N}$ & $\mathbf{N}$ \\
\hline 46 & $30 \mathrm{~F}$ & 2 & & & $\mathbf{N}$ & & $\mathbf{N}$ \\
\hline 47 & $71 \mathrm{M}$ & 2 & & $\mathbf{N}$ & & $\mathbf{N}$ & \\
\hline
\end{tabular}

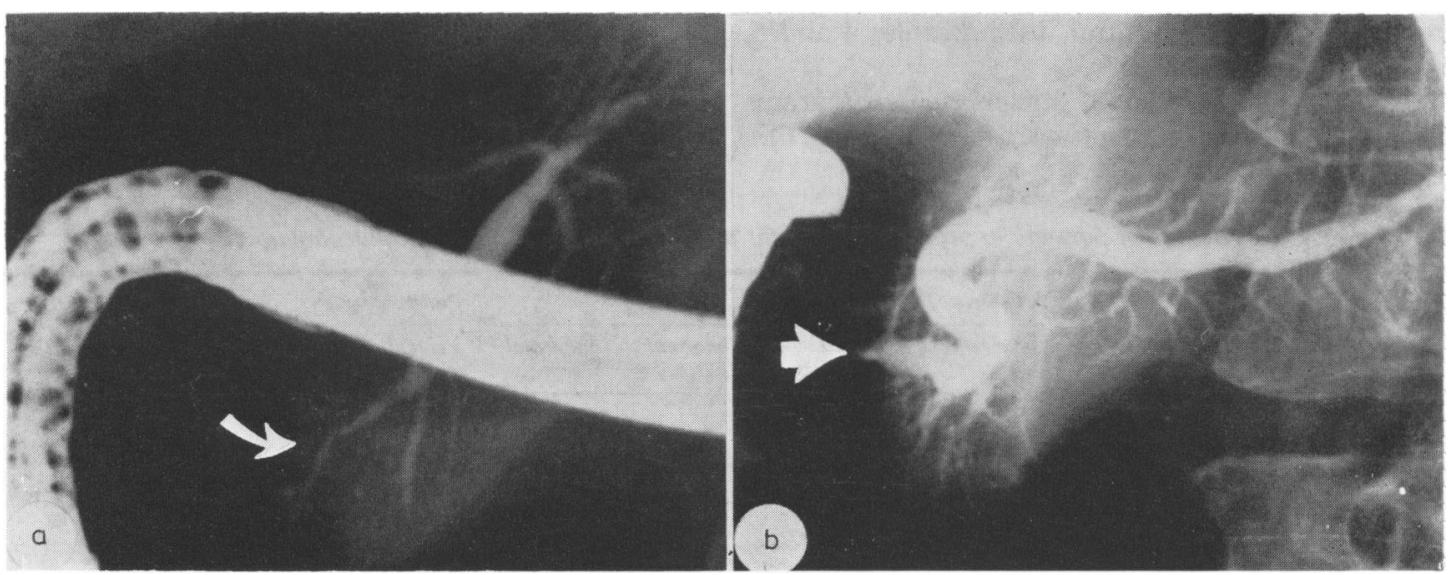

Fig. 7 (a) Normal ventral system after cannulation of the main papilla. (b) Same patient. Cannulation of the accessory papilla (arrowed) has outlined the dorsal system; the main duct and its branches are abnormally dilated.

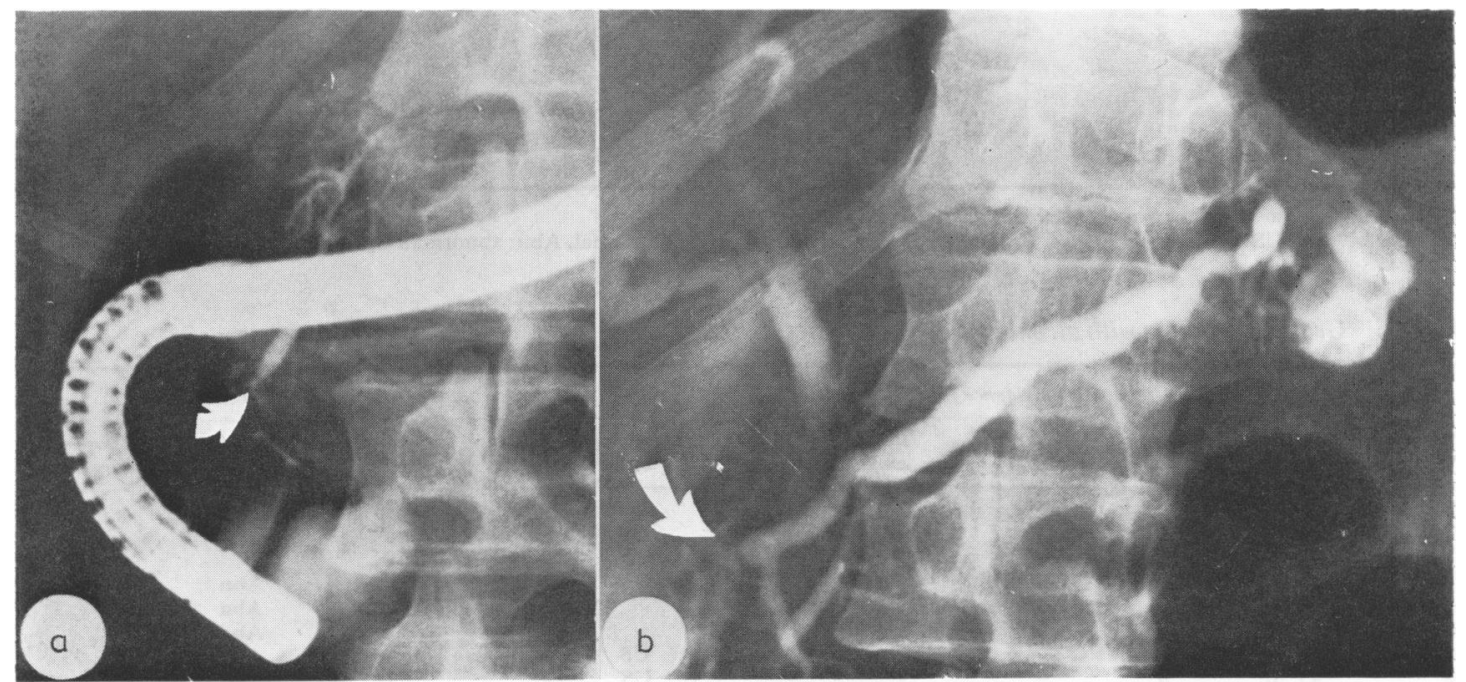

Fig. 8 Another patient with a normal ventral duct system, and a pathological dorsal system. (a) Ventral system outlined after cannulating the main papilla (arrow). (b) Grossly dilated dorsal system after cannulation of the accessory papilla (arrowed), and a cyst in the tail of the pancreas. 
Table 7 Attempts at cannulating accessory papilla to obtain dorsal pancreatogram via Santorini's duct

\begin{tabular}{lll}
\hline & With ventral & Without ventral \\
\hline Not attempted & 12 & 0 \\
Failed & 17 & 0 \\
Succeeded & 10 & 8 \\
\hline
\end{tabular}

gone pancreatic surgery at other hospitals without benefit.

Eight of the 19 patients with pancreatitis unassociated with alcohol (group B) have subsequently undergone specific pancreatic procedures. Six had pancreatic operations, of which details will be published elsewhere, and two underwent endoscopic
Fig. 9. Example of pancreas divisum without a detectable ventral element (see Fig. 1D). Abnormal dorsal duct system with delayed drainage through the accessory papilla (large arrow). The bile duct has been filled previously via the main papilla (small arrow).

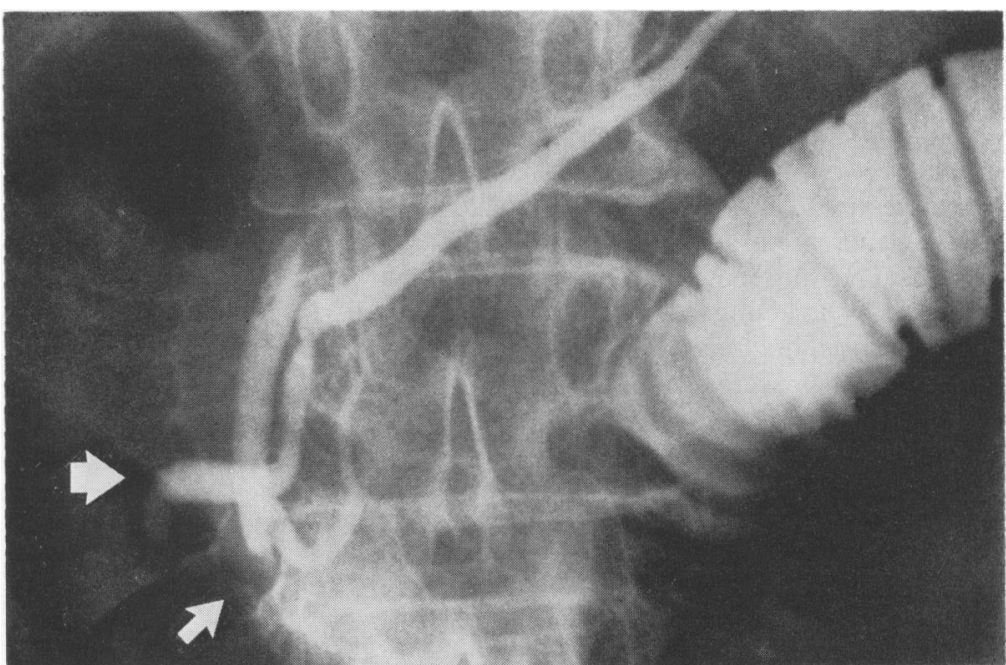

Table 8 Incidence of pancreas divisum from necropsy pancreatography

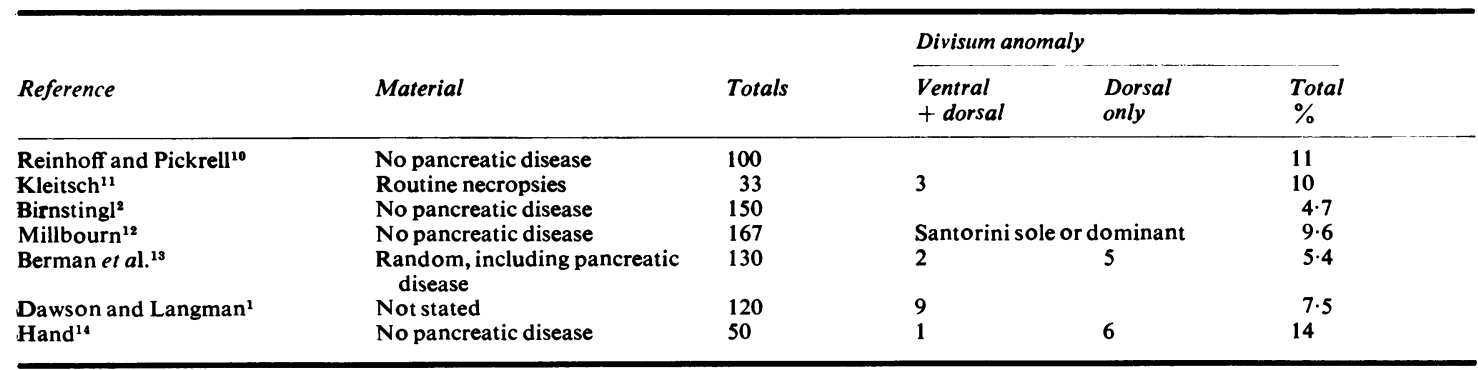

Table 9 Published series on incidence of pancreas divisum at ERCP

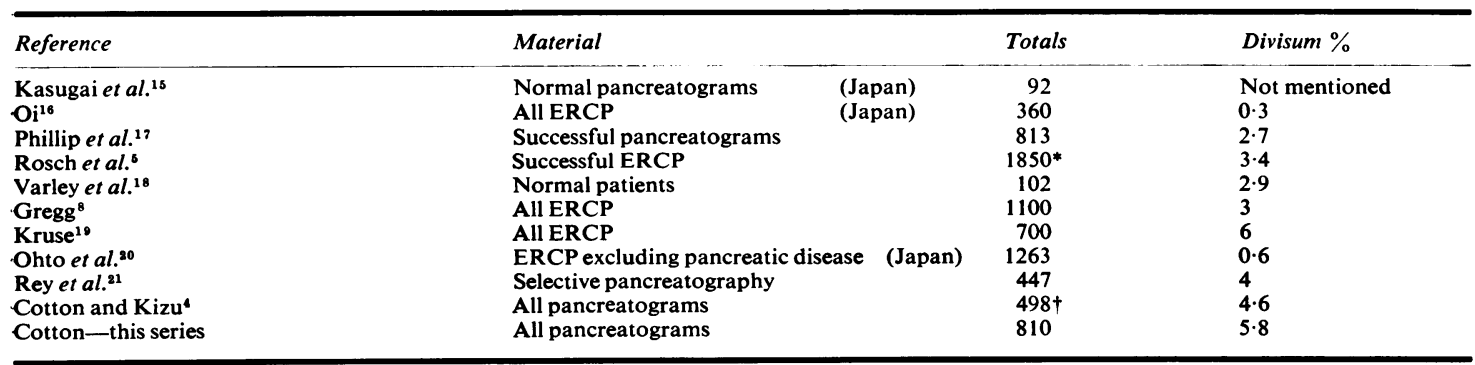

*The figures of Rosch et al. include those of the preceding series from the same group (Phillip et al.)

†The series of Cotton and Kizu started before the present series, and included patients from a previous hospital. 
sphincterotomy at the accessory papilla.

\section{PANCREATIC HISTOLOGY}

Histological examination has shown pancreatitis in all available surgical specimens of the dorsal pancreas. Only two specimens of the ventral part of the pancreas have been obtained. Many surgeons have not recognised the presence or possible significance of the anomaly; even so doing, few would feel justified in taking specimens from the one area of the pancreas which should be normal. One alcoholic patient (Table 5, no. 35) underwent total pancreatectomy at another hospital, but it has not been possible to identify the source of the various histological sections. Another patient (Table 4, no. 18) had a pancreatico-duodenectomy (Whipple's procedure). The different parts of the specimen were identified by injecting the dorsal duct system. Periductal fibrosis, duct epithelial metaplasia, and small cyst formations were evident in sections from the dorsal part of the gland, but not from the ventral part.

\section{Discussion}

The congenital duct anomaly of pancreas divisum may be important for several reasons. Firstly, the inexperienced can mistake the radiographic appearances of a ventral pancreas for those of duct obstruction due to carcinoma..$^{5}$ Secondly, whether or not the anomaly is aetiologically important, it is present in many patients with recurrent pancreatitis (16.4\% overall in this series). Failure to recognise the anomaly may result in anatomically inappropriate operations. For instance, two patients in this series had undergone surgical sphincteroplasty at the major papilla; it is scarcely surprising that these procedures were unhelpful, as drainage was mainly through the accessory system.

It may be difficult even for the initiated to detect the anomaly on an operative pancreatogram performed from the tail of the gland, as Santorini's duct may then resemble a normal Wirsung's system (Fig. 5). This is another reason for using ERCP in all patients with recurrent pancreatitis who are being considered for surgery. ${ }^{7}$

The most interesting question concerning pancreas divisum is whether the duct anomaly can itself lead to symptoms. There are several different strands of evidence to support the hypothesis that the accessory papilla and Santorini's duct are too small to accept total pancreatic secretion, resulting eventually in obstructive pain and pancreatitis. ${ }^{4,8,9}$

At first sight, the epidemiological data are unimpressive. Although criticisms can be made of various necropsy series, they suggest that one or other form of pancreas divisum may be present in $5-10 \%$ of subjects (Table 8). The overall figures from ERCP are lower (Table 9) which is scarcely consistent with the theory that the anomaly causes pancreatic problems. However, many ERCP examinations are performed for purely biliary symptoms, and the mix of indications for ERCP varies in different series. Pancreatitis is rare in Japan, and Japanese ERCP series show a very low incidence of pancreas divisum (Table 9). Subdivision of ERCP series by indication provides more convincing epidemiological evidence. In this series, there was a $25.6 \%$ incidence of pancreas divisum among patients with idiopathic recurrent pancreatitis' (all those with pancreatitis without evidence of alcohol abuse, gallstones, or trauma) which is significantly greater $(P=<1.0001)$ than the incidence of only $3.6 \%$ in patients with primary biliary tract problems undergoing pancreatography incidental to endoscopic cholangiography (Table 1). This high figure of $25.6 \%$ may partly reflect case selection. Many patients are referred to us with difficult problems in pancreatic diagnosis and management, and some in whom ERCP has failed elsewhere. The extent of any selection bias cannot be calculated, but the percentage of previous ERCP failures was similar in the groups of patients with and without anomalies. Conversely, the figure of $25.6 \%$ may even underestimate the importance of the anomaly; some of the patients with 'idiopathic recurrent pancreatitis' may have had an alcohol problem which had not been detected (by very careful enquiries) and other patients in whom pancreatography failed completely may also have had pancreas divisum. In most ERCP series there is a $10-15 \%$ failure rate for pancreatography, and a proportion of these patients may have unrecognised anomalies of the type illustrated in Fig. 1D. Such cases can be detected only by routine accessory cannulation when cannulation of the major papilla fails to show the pancreas. This need has been appreciated only recently, and accessory cannulation is technically difficult. We succeeded in obtaining a dorsal pancreatogram by this route in 18 of 35 attempts (Table 7). In one patient it was possible to cannulate the accessory orifice only after removing the papilla itself with a diathermy snare. Others have reported accessory cannulation success rates of seven out of $18,{ }^{17}$ four out of 15,8 and four out of 10. 21

The obstructive hypothesis would be strengthened by showing that pancreatic abnormalities (on radiology, scanning, function testing, or histology) were restricted to the dorsal segment, the ventral part remaining healthy. The interpretation of minor changes of pancreatitis at endoscopic pancreato- 
graphy is controversial ${ }^{3}$ and the distinction between normal and slightly abnormal radiographs is often difficult. However, according to our criteria based on extensive experience, seven of our 19 patients with pancreatitis unassociated with alcohol abuse (group B) had abnormal dorsal but normal ventral pancreatograms (Table 4). Similar findings were evident in one patient with alcohol associated pancreatitis (group C, Table 5) but, in another, both ducts were abnormal. However, a normal pancreatogram is not inconsistent with pancreatic pain or even pancreatitis.

Neither ultrasonography nor computed tomography proved to be precise enough to give differential information about the dorsal and ventral parts of the pancreas. However, we found these scanning techniques (particularly ultrasonography) helpful in confirming the presence of pancreatitis when ERCP showed only a normal ventral duct system. Differential pancreatic function studies are virtually impossible technically, ${ }^{8}$ it would be necessary to pass catheters deep into both ventral and dorsal duct systems in the same patient. Even then, it is doubtful whether present biochemical indices are sufficiently sensitive to demonstrate a convincing difference between the two parts of the pancreas, and any difference would be difficult to interpret. Differential histology is rarely available. However, in one of our patients (Table 4, no. 18) who underwent a Whipple's procedure, it was possible to show changes of pancreatitis in the dorsal segment which were not evident in the ventral part.

Additional evidence for the obstructive hypothesis should come from the clinical results of improving drainage of the dorsal duct system. Surgical sphincterotomy at the accessory papilla has sometimes been successful, although re-stenosis can occur ${ }^{9}$ (Warren, personal communication). The fact that the dorsal pancreatic duct system is often not markedly dilated means that distal duct drainage procedures are technically difficult, and may be of only temporary benefit. One of our patients (Table 4, no. 22) had a surgical accessory sphincterotomy which stenosed, followed by a pancreatico-jejunostomy using a non-dilated duct; this produced only temporary benefit. Our surgical approach to these patients is still being evaluated and will be discussed elsewhere. However, it seems that partial pancreatic resection is often necessary. Sphincterotomy at the accessory papilla has been performed endoscopically in two patients. ${ }^{22} \mathrm{Re}$-stenosis occurred within weeks in both patients, and the procedures were repeated; in one case with long-term benefit.

The association between pancreas divisum and pancreatitis has been reported by other groups. ${ }^{5}, 8,9,18,21$ Rosch and colleagues stated in
$1974^{5}$ that 13 of 63 patients with pancreas divisum had radiographic evidence of pancreatitis, but they did not suggest an aetiological relationship. Gregg reported 33 patients with pancreas divisum; 15 had pancreatitis (attributable to alcohol abuse in only two cases) and 11 had obscure pancreatic type pain. ${ }^{8}$ Heiss and Shea $^{9}$ described four patients with pancreatitis in whom no other explanation was evident apart from the duct anomaly.

To complicate the situation, we have another series of problem patients with pancreatic duct arrangements intermediate between those of normality (Fig. 1C) and pancreas divisum (Fig. 1B); the dorsal and ventral duct systems communicate, but only in a rudimentary fashion, so that drainage is virtually all through Santorini's duct and the accessory papilla. These patients present in similar ways to those with pancreas divisum and need further study.

These different strands of evidence add up to a convincing case for the hypothesis that the congenital pancreatic duct anomalies involved in pancreas divisum can cause obstructive pancreatic pain and pancreatitis. Recognition and further study of this situation should lead to the effective treatment of a small group of patients with distressing and hitherto ill-understood symptoms.

I am grateful to many clinicians for referring patients, and to numerous colleagues for contributing in various ways to their investigation. I wish particularly to thank Dr M Chapman, Mr R C G Russell, Dr M Kizu, Dr M Denyer, Dr A G Vallon, and Dr W R Lees.

\section{References}

${ }^{1}$ Dawson W, Langman J. An anatomical-radiological study on the pancreatic duct pattern in man. Anat Rec $1961 ; 139$ : 59-68.

${ }^{2}$ Birnstingl M. A study of pancreatography. Brit J Surg 1959; 47: 128-39.

${ }^{3}$ Cotton PB. ERCP. Gut 1977; 18: 316-41.

${ }^{4}$ Cotton PB, Kizu M. Malfusion of dorsal and ventral pancreas. A cause of pancreatitis? (Abstract) Gut $1977 ; 18: 400$.

${ }^{5}$ Rösch W, Koch H, Schaffner O, Demling L. The clinical significance of the pancreas divisum. Gastrointest Endosc 1976; 22 : 206-7.

${ }^{6}$ Belber JP, Bill K. Fusion anomalies of the pancreatic ductal system. Differentation from pathologic states. Radiology 1977; 122: 637-42.

${ }^{7}$ Cotton PB, Beales JSM. Endoscopic pancreatography in management of relapsing acute pancreatitis. Br Med J 1974; 1: 608-11.

${ }^{8}$ Gregg JA. Pancreas divisum. Its association with pancreatitis. Am J Surg 1977; 134: 539-43.

${ }^{9}$ Heiss FW, Shea JA. Association of pancreatitis and variant ductal anatomy. Amer J Gastroenterol 1978; 70: 158-62. 
${ }^{10}$ Rienhoff WF Jr, Pickrell KL. Pancreatitis. An anatomic study of the pancreatic and extra-hepatic biliary systems. Arch Surg 1945; 51 : 205-19.

"Kleitsch WP. Anatomy of the pancreas. A study with special reference to the duct system. Arch Surg 1955; 71 : 795-802.

${ }^{12}$ Millbourn E. Calibre and appearance of the pancreatic ducts and relevant clinical problems. A roentgenographic and anatomical study. Acta Chir Scand 1959/60; 118: 286-303.

${ }^{13}$ Berman LG, Prior JT, Abramow SM, Ziegler DD. A study of the pancreatic duct system in man by the use of vinyl acetate casts of postmortem preparations. Surg Gynec Obstet 1960; 110: 391-403.

${ }^{14} \mathrm{Hand}$ BH. An anatomical study of the choledochoduodenal area. Brit J Surg 1963; 50: 486-94.

${ }^{15}$ Kasugai T, Kuno N, Kobayashi S, Hattori K. Endoscopic pancreatocholangiography. I. The normal endoscopic pancreatocholangiogram. Gastroenterology $1972 ; 63: 217-226$.
${ }^{16} \mathrm{Oi} \mathrm{I}$. Techniques of endoscopic pancreatocholangiography. (In Japanese) Tokyo: Igaku Shoin, 1973.

${ }^{17}$ Phillip J, Koch H, Classen M. Variations and anomalies of the papilla of Vater, the pancreas and the biliary duct system. Endoscopy 1974; 6: 70-7.

${ }^{18}$ Varley PF, Rohrmann CA Jr, Silvis SE, Vennes JA. The normal endoscopic pancreatogram. Radiology 1976; 118: 295-300.

${ }^{19}$ Kruse A. Pancreas divisum. A significantly high incidence in chronic pancreatitis? Scand $J$ Gastroenterol $1977 ; 12$ : suppl 45 : 52.

${ }^{20}$ Ohto M, Ono T, Tsuchiya Y, Saisho H. Cholangiography and pancreatography, New York: Igaku Shoin, 1978.

${ }^{21}$ Rey JF, Blanc-Mouille C, Garnier C, Delmont J. Le pancréas divisum; realité anatomique et source de lésion pancréatique. Ann Gastroenterol Hépatol 1978; 14: 196-7.

${ }^{22}$ Cotton PB. Duodenoscopic papillotomy at the minor papilla for recurrent dorsal pancreatitis. Endoscop Digest 1978; 3: 27-8. 